\title{
Centenário da Lei de Acidentes de Trabalho: análise sobre acidentes em fábricas de tecidos do Rio de Janeiro na Primeira República
}

Centenary of the Law of Labor Accidents: analysis of accidents in textile factories in Rio de Janeiro in the First Republic

\section{Isabelle Cristina da Silva Pires*}

Resumo: O presente artigo procura ressaltar o centenário da promulgação do Decreto $\mathrm{n}^{\circ}$ 3.724, de 15 de janeiro de 1919, que regulava as obrigações resultantes dos acidentes de trabalho. Está dividido em duas partes: na primeira, analiso e apresento alguns debates acerca das condições de trabalho que acarretavam acidentes em fábricas de tecidos no Rio de Janeiro, então Distrito Federal, nas primeiras décadas do século XX; na segunda, examino o contexto de promulgação dessa lei e sua aplicação por parte dos industriais têxteis, membros da Sociedade Cooperativa de Seguros Operários em Fábricas de Tecidos.

Palavras-chave: Legislação; acidentes de trabalho; operários têxteis.

Abstract: This article seeks to highlight the centenary of the promulgation of Decree No. 3,724 of January 15, 1919, which regulated the obligations arising from labor accidents. It is divided into two parts: in the first, I analyze and present some debates about the working conditions that caused accidents in textile factories in Rio de Janeiro, Federal District, in the first decades oh the 20th century; in the second, I examine the context of enactment of this Law and its application by the textile industrialists who were part of the Sociedade Cooperativa de Seguros Operários em Fábricas de Tecidos.

Keywords: Legislation; labor accidents; textile workers.

Doutoranda em História Social pelo PPGHIS/UFRJ. Bolsista CAPES. Mestre em História, Política e Bens Culturais pelo CPDOC/FGV. Graduação em História pela UFRRJ. E-mail: isabellecspires@gmail.com. ORCID: https://orcid.org/0000-0002-4554-9529. 


\section{Introdução}

Em maio deste ano de 2019, o atual Presidente da República, Jair Bolsonaro, anunciou a intenção de reduzir em $90 \%$ as Normas Regulamentadoras (NR) de segurança e saúde no trabalho. Alegando que tal proposta tem como intuito "desburocratizar" o setor, o governo federal pretende rever normas do âmbito do Direito do Trabalho, cuja proteção vinha sendo assegurada na CLT, na Constituição Federal e em acordos firmados em tratados internacionais, como as convenções da Organização Internacional do Trabalho (OIT). ${ }^{1}$

Conforme estabelecido na Lei $n \div 0$ 8.213/91, são caracterizados atualmente como acidentes de trabalho os eventos ocorridos no exercício da atividade laboral, provocando lesão corporal ou disfunção que cause a morte, a perda ou a redução, permanente ou temporária da capacidade para o trabalho. Ainda são consideradas as doenças adquiridas por conta do exercício da função e o acidente sofrido no percurso casa-trabalho-casa.

O campo da proteção à saúde e da seguridade no trabalho no Brasil passou por discussões e implementação de decretos e normas no setor legislativo e também foi influenciado pelos acordos internacionais firmados nos congressos da OIT, ao longo do século XX, até os dias de hoje. Simone Andrietta aponta que a proteção ao acidente de trabalho tem estreita relação com o bem-estar social e ganhou, no decorrer do século XX, respaldo jurídico de que o Estado arcaria com a função social de garantir a dignidade humana, protegendo o/a trabalhador/a com benefícios que o/a amparassem diante das adversidades. ${ }^{2}$

As disputas desse campo são pujantes e em períodos de crise do capitalismo os debates em torno da proteção ao trabalho se direcionam para o afrouxamento das medidas de segurança. Com isso, a ocorrência de acidentes de trabalho e de doenças decorrentes da função exercida está diretamente atrelada ao processo de exploração, o que se torna mais evidente em momentos de crise econômica, frequentemente solucionados com o aumento da jornada de trabalho, a redução das medidas preventivas, o relaxamento da fiscalização, entre outras formas de favorecimento das necessidades do capital. Por conta dessa flexibilização das medidas de proteção, aliada ao processo de exploração do trabalho na ditadura

\footnotetext{
NASCIMENTO, Marcelo Mascaro. Revisão de normas prometida por Bolsonaro aumentará acidentes de trabalho? Exame, 30 mai. 2019. Disponível em: https://exame.abril.com.br/carreira/revisao-de-normas-prometida-por-bolsonaro-aumentaraacidentes-de-trabalho/. Acesso em: 17 jun. 2019.

2 ANDRIETTA, Simone Aparecida de Oliveira. Acidente do trabalho: histórico legislativo e a proteção dos direitos do cidadão. 2009. Dissertação (Mestrado em Direito) - Universidade Metodista de Piracicaba, 2009. p. 15.
} 
militar, o Brasil foi considerado, na década de 1970, o recordista mundial em acidentes de trabalho, mesmo que a estatística tenha se pautado em números manipulados e subestimados. ${ }^{3}$

Ante o cenário retratado, este artigo tem como objetivo contribuir para os debates acerca dos acidentes de trabalho na indústria brasileira ${ }^{4}$, ressaltando o centenário do Decreto ํㅜ 3.724 , de 15 de janeiro de 1919, que regulava as obrigações resultantes desses acidentes, ato este produto das discussões que tomaram forma na conjuntura das greves de 1917 a 1919. Para tanto, divido este artigo em duas partes: no primeiro momento, proponho analisar e apresentar alguns debates sobre as condições de trabalho que ocasionavam acidentes em fábricas de tecidos no Rio de Janeiro, então Distrito Federal, nas primeiras décadas do século XX; no segundo, busco examinar o contexto de promulgação do referido decreto e sua aplicação por parte dos industriais têxteis, membros da Sociedade Cooperativa de Seguros Operários em Fábricas de Tecidos.

Para tal, utilizo como fontes os jornais A Epoca, A Noite, A Noticia, A Razão, Correio da Manhã, Gazeta de Noticias, Jornal do Brasil e O Paiz; o texto do Decreto n. 3.724 de 15 de janeiro de 1919 e os Relatórios da Sociedade Cooperativa de Seguros Operários em Fábricas de Tecidos de 1921 a 1926. Nos periódicos, procuro informações que permitam extrair reflexões sobre os acidentes de trabalho e a conjuntura de promulgação do decreto. Já nos relatórios da cooperativa de seguros busco perceber as estratégias adotadas pelos industriais para assegurar a mão de obra acidentada.

$\mathrm{Na}$ amostra apresentada, encontram-se periódicos que se distinguem quanto ao posicionamento em relação ao governo e quanto ao espaço dado a questões sociais e trabalhistas. O jornal A Epoca, fundado em 1912, de viés anti-oligárquico, era um veículo de oposição ao governo de Hermes da Fonseca e ao diário O Paiz; trazia em suas páginas certo destaque ao movimento operário, com colunas para abordar as condições da classe trabalhadora. ${ }^{5} \mathrm{O}$ vespertino $A$ Noite, fundado por Irineu Marinho, após ter deixado a Gazeta de Noticias, era considerado um dos

3 SILVA, Ana Beatriz Ribeiro Barros. Brasil, o "campeão mundial de acidentes do trabalho": controle social, exploração e prevencionismo durante a ditadura empresarial-militar brasileira. Revista Mundos do Trabalho, v. 7, n. 13, jan.-jun., p. 161-164, 2015.

4 FERRAZ, Eduardo Luís Leite. Acidentados e remediados: a lei de acidentes no trabalho na Piracicaba da Primeira República (1919-1930). Revista Mundos do Trabalho, v. 2, n. 3, jan.-jul., 2010; MOURA, Esmeralda Blanco B. de. Infância operária e acidente do trabalho em São Paulo. In: PRIORE, Mary Del (org.). História das crianças no Brasil. São Paulo: Contexto, 1991; OLIVEIRA, Newton C. de. A economia do sinistro: contribuição ao estudo dos acidentes de trabalho na indústria têxtil durante o Estado Novo, 1937-1945. 1993. Dissertação (Mestrado em História) Universidade Federal Fluminense, 1993; SILVA, op. cit.

5 BRASIL, Bruno. A Época (Rio de Janeiro, 1912). Disponível em: http://bndigital.bn.gov.br/artigos/aepoca/. Acesso em: 12 ago. 2019. 
primeiros jornais populares do Rio de Janeiro, atribuindo destaque para o noticiário policial. ${ }^{6} \mathrm{O}$ vespertino republicano $A$ Noticia priorizava a informação de caráter geral, em detrimento das questões políticas, desde sua fundação, em 1894, até 1924, quando se tornou porta-voz acrítico do governo. ${ }^{7}$ A Razão era um jornal oficial da doutrina conhecida como racionalismo cristão; apesar de dar certo destaque ao movimento operário em geral, era considerado conservador e governista. ${ }^{8}$ Reconhecido como um "jornal de opinião", o Correio da Manhã era uma folha de oposição à situação e uma de suas características era a aproximação com as camadas menos favorecidas da sociedade. ${ }^{9}$ A Gazeta de Noticias, no início do século XX, assumiu com maior nitidez seu caráter situacionista, mas opôs-se a certas determinações do governo federal, como a vacinação obrigatória (1904) e a obrigatoriedade do serviço militar. ${ }^{10}$ O Jornal do Brasil, entre 1894 e 1914, declarouse situacionista, mas paralelamente, propunha-se a ser um veículo de comunicação "popular", "... defensor dos pobres e dos oprimidos e divulgador de suas queixas e reclamações". ${ }^{11}$ Apesar de ser um jornal conhecido por seu "situacionismo subserviente",12 O Paiz se encontra nessa amostra pela relevância de suas matérias que retratavam o cotidiano do Rio de Janeiro. De modo geral, todos esses veículos de imprensa publicavam matérias sobre tragédias cotidianas e alguns, como mencionado, dedicavam certa atenção à causa operária. Assim, tais periódicos nos permitiram ter acesso a notícias sobre acidentes sofridos por trabalhadores/as em fábricas e sobre debates envolvendo a temática.

\section{O problema dos acidentes no trabalho e seus debates}

O ramo têxtil algodoeiro foi a principal atividade do setor industrial do Brasil antes de 1914, segundo Flavio Versiani, e seu desenvolvimento teria se dado, sobretudo, por meio de duas fontes: a instabilidade da taxa de câmbio, que teria

6 BRASIL, Bruno. A Noite (Rio de Janeiro, 1911). Disponível em: https://bndigital.bn.gov.br/artigos/anoite/ Acesso em: 13 ago. 2019.

7 LUCA, Tania Regina de. A grande imprensa no Brasil da primeira metade do século XX. In: LUCA, Tania Regina; MARTINS, Ana Luiza. (org.). História da imprensa no Brasil. São Paulo: Contexto, 2008. v. 1, p. 159.

8 BRASIL, Bruno. A Razão (Rio de Janeiro, 1916). Disponível em: https://bndigital.bn.gov.br/artigos/arazao-rio-de-janeiro-1916/ Acesso em: 12 ago. 2019.

9 LEAL, Carlos Eduardo. Correio da Manhã [verbete]. Disponível em: http://www.fgv.br/cpdoc/acervo/dicionarios/verbete-tematico/correio-da-manha. Acesso em: 13 ago. 2019.

10 LEAL, Carlos Eduardo. Gazeta de Noticias [verbete]. Disponível em: http://www.fgv.br/cpdoc/acervo/dicionarios/verbete-tematico/gazeta-de-noticias Acesso em: 13 ago. 2019.

11 FERREIRA, Marieta de Moraes; MONTALVÃO, Sérgio. Jornal do Brasil [verbete]. Disponível em: http://www.fgv.br/cpdoc/acervo/dicionarios/verbete-tematico/jornal-do-brasil Acesso em: 13 ago. 2019.

12 LUCA, op. cit., p. 163. 
estimulado os comerciantes de tecidos a atuar no setor de produção têxtil; e um sistema tarifário protecionista, que teria possibilitado a permanência e a ampliação da indústria brasileira no período. ${ }^{13}$

A cidade do Rio de Janeiro teve forte proeminência no processo de desenvolvimento da indústria têxtil no Brasil, a partir de 1880, quando se tornou o principal centro industrial e financeiro do país. Na mesma década, fundaram-se na região companhias têxteis que vieram a ser as maiores do Brasil, até a década de 1910, e mantiveram-se como as principais do Distrito Federal até, pelo menos, os últimos anos da Primeira República.

O primeiro levantamento geral do setor manufatureiro no país foi feito pelo Centro Industrial do Brasil, em 1907. O documento identificou que a cidade do Rio de Janeiro abrigava a maior concentração de empreendimentos industriais do país, isto é, cerca de $1 / 5$ da indústria nacional. As fábricas de tecidos empregavam $52 \%$ da força de trabalho dos estabelecimentos manufaturados, com 200 operários ou mais. ${ }^{14}$

$\mathrm{Na}$ década de 1880, foram criados estabelecimentos fabris têxteis que despontaram entre os principais do país na Primeira República, sendo eles:

Companhia Progresso Industrial do Brasil, cuja fábrica foi instalada em Bangu, a Fábrica de Fiação, Tecidos e Tinturaria Aliança (Laranjeiras), a Companhia de Fiação e Tecidos Confiança Industrial (Vila Isabel), a Companhia de Fiação e Tecidos Corcovado (Jardim Botânico) e a Companhia de Fiação e Tecelagem Carioca (Jardim Botânico - Horto). ${ }^{15}$

Entre os anos de 1885 e 1895, ocorreu um forte investimento no setor, seja em novas fábricas, seja em aumento da capacidade já instalada, visto que, em relação ao número de teares que as maiores fábricas têxteis do Rio de Janeiro possuíam até 1884 , a década seguinte aumentou em 4,5 vezes o estoque do equipamento. ${ }^{16}$

No entanto, apesar do avanço em maquinaria e da expansão do setor que proporcionava mais vagas de emprego para homens, mulheres e crianças, as fábricas de tecidos ofereciam ambientes insalubres por serem espaços fechados, onde se respirava o mesmo ar por longas horas, misturado a detritos de algodão.

13 VERSIANI, Flávio Rabelo. Industrialização e economia de exportação: a experiência brasileira antes de 1914. Revista Brasileira de Economia, v. 34, no 1, 1980. p. 3.

14 Ibidem, p. 7.

15 LAMARÃO, Sérgio Tadeu de Niemeyer. A energia elétrica e o parque industrial carioca (1880-1920). In: Simpósio Internacional Globalización, Innovación y Construcción de Redes Técnicas Urbanas em América y eUropa, 1890-1930: Brazilian Traction, Barcelona Traction y Otros Conglomerados Financieros y Técnicos. Anais.... Barcelona: Universidad de Barcelona, 2012. p. 7. Disponível em: http://www.ub.edu/geocrit/Simposio/cLamarao_Aenergia.pdf. Acesso em: 17 jun. 2019.

16 VERSIANI, Flávio Rabelo; VERSIANI, Maria Teresa R. O. A industrialização brasileira antes de 1930: uma contribuição. In: VERSIANI, Flávio Rabelo; BARROS, José Roberto Mendonça de. (org.). Formação econômica do Brasil: a experiência da industrialização. São Paulo: Saraiva, 1978. p. 129. 
Alguns estabelecimentos se encontravam em melhores condições que outros, mas, de modo geral, o próprio processo de produção de tecidos já criava um ambiente prejudicial à saúde. Nas fábricas têxteis, além das chamadas doenças profissionais, ocasionadas em virtude do exercício da atividade, os/as trabalhadores/as ainda estavam sujeitos às consequências da falta de medidas destinadas à preservação da saúde e de acidentes.

Em estudo baseado, sobretudo, nos boletins do Departamento Estadual do Trabalho, Esmeralda Blanco B. de Moura destaca as principais causas de acidentes de trabalho em fábricas de São Paulo, entre os anos 1890 a 1919. Ela relata que, além das condições de trabalho, com longas jornadas, insalubridade dos estabelecimentos industriais e, muitas vezes, ausência de descanso semanal, em 1913, o órgão definia como principal causador de acidentes no trabalho industrial a ausência quase total de equipamentos de proteção. No ano anterior, o Departamento declarara que muitos acidentes poderiam ser evitados, caso uma tela fosse colocada ao redor das máquinas e das correias transmissoras de força. ${ }^{17}$

Dentre os casos de acidentes, apontados na presente pesquisa, ocorridos nas principais fábricas de tecidos do Distrito Federal, também percebo que uma das principais causas era a falta de proteção do maquinário e o seu mau funcionamento. Tais motivos levaram os operários Manuel Rodrigues e James Hathaway a sofrerem fraturas e terem de ser hospitalizados:
Com um braço fracturado um operario
Manuel Rodrigues, operário da Fabrica de Tecidos Alliança, nas Laranjeiras, ante-hontem, á tarde, foi alcançado por uma polia, ficando com o braço esquerdo fracturado.
Manuel, que tem 32 annos, é casado e morador á rua Cardoso Junior, foi socorrido na Assistencia, recolhendo-se de pois á sua residência. ${ }^{18}$
$\mathrm{Na}$ Fabrica de Tecidos Corcovado verificou-se hontem um desastre funesto para o operario James Hathaway.
Trabalhava elle em um tear, quando um dos pistons saltou do logar, caindo-lhe sobre o braço esquerdo, fracturando-o.
O ferido foi recolhido ao Hospital dos Inglezes, depois de medicado na Assistencia. ${ }^{19}$

Durante o processo de produção de tecidos, os/as operários/as deveriam permanecer perto das máquinas para verificar seu funcionamento e se o fio não havia se rompido. Portanto, exercendo suas funções, esses trabalhadores foram atingidos por peças de máquinas que se soltaram por mau funcionamento.

\footnotetext{
17 MOURA, Esmeralda Blanco de. Mulheres e menores no trabalho industrial: os fatores sexo e idade na dinâmica do capital. Petrópolis, RJ: Vozes, 1982. p. 49-50.

18 DESASTRES. Jornal do Brasil, Rio de Janeiro, 17 abr. 1910. p. 15.

19 NA FABRICA de Tecidos Corcovado. A Noite, Rio de Janeiro, 25 nov. 1911. p. 3.
} 
No primeiro caso, o operário da Fábrica Alliança, localizada no bairro de Laranjeiras, após ser medicado e levado para casa, provavelmente, se ausentou do trabalho para recuperar-se, sem vencimentos. Em um período em que não havia legislação que assegurasse o/a trabalhador/a acidentado/a, Manuel apenas contaria com algum apoio financeiro, caso fizesse parte de algum sindicato ou associação mutualista que o amparasse. ${ }^{20} \mathrm{O}$ segundo caso é o único dos apresentados neste artigo em que, depois de medicado pela Assistência, o acidentado foi levado para receber maiores cuidados no Hospital dos Ingleses. Em virtude de seu nome e sobrenome e por ter sido encaminhado para tal hospital, é possível inferir que o operário era inglês e que era filiado a uma sociedade mutualista que lhe permitia tratamento no Hospital dos Ingleses, visto que, segundo Gisele Sanglard, esse hospital estava ligado a uma entidade de auxílio mútuo. ${ }^{21}$

Havia casos também em que o manejo da máquina deveria atrair a máxima atenção, visto que ao mínimo descuido, em virtude da periculosidade do equipamento, as consequências poderiam ser drásticas. Assim, o operário português Bonifacio Ferreira, de 50 anos, fraturou a mão direita na máquina de secar panos, no início do expediente, às 6 horas da manhã, na Fábrica de Tecidos Carioca, localizada no bairro do Jardim Botânico. Ele foi medicado pela Assistência e depois transferido para a Santa Casa, onde iniciou tratamento. ${ }^{22}$ Diferente dos dois casos anteriores, em que os trabalhadores foram vítimas de peças que se soltaram, Bonifacio feriu a mão por conta do risco da função que desempenhava, risco este que poderia ser minimizado caso alguns dispositivos de segurança fossem incorporados para preservar a integridade do/a executante.

Refletindo sobre as condições de trabalho e a organização da produção fabril no Rio Grande do Sul, entre 1889 e 1920, Evangelia Aravanis aponta como causas dos acidentes, além da falta de manutenção das máquinas, a falta de equipamentos de proteção corporal e a alta periculosidade das unidades fabris, com seções contendo produtos químicos que podiam explodir ou gerar queimaduras. ${ }^{23}$

20 Para saber mais sobre associações mutualistas, ver: JESUS, Ronaldo Pereira de. Historiografia sobre mutualismo (1875-1914) em Portugal e no Brasil. Estudos Ibero-Americanos, Porto Alegre, v. 42, n. 3, 2016; MAC CORD, Marcelo, BATALHA, Claudio H. M. (org). Organizar e proteger: trabalhadores, associações e mutualismo no Brasil (séculos XIX e XX). Campinas: Editora da Unicamp, 2014; VISCARDI, Cláudia Maria Ribeiro. Estratégias populares de sobrevivência: o mutualismo no Rio de Janeiro republicano. Revista Brasileira de História, São Paulo, v. 29, n. 58, 2009.

21 SANGLARD, Gisele. Hospitais: espaços de cura e lugares de memória da saúde. Anais do Museu Paulista, São Paulo, v.15. n.2, p. 257-289. jul.-dez. 2007. p. 261.

22 ACCIDENTE no trabalho. A Noticia, Rio de Janeiro, 17-18 ago. 1911. p. 2.

23 ARAVANIS, Evangelia. A industrialização no Rio Grande do Sul nas primeiras décadas da República: a organização da produção e as condições de trabalho (1889-1920). Revista Mundos do Trabalho, v. 2, n. 3, jan.-jul., 2010. p. 169-170. 
Os acidentes de trabalho são um fenômeno proeminente das relações capitalistas de produção e, nesse período, não havia uma interferência maior do Estado que regulasse e fiscalizasse as dinâmicas do trabalho, motivo pelo qual os operários de diferentes partes do país enfrentavam perigos semelhantes e estavam expostos aos mesmos riscos ao manejar máquinas fabris.

No processo de produção de tecidos, havia seções nas quais eles lidavam com substâncias químicas, como dito anteriormente, provocando risco de intoxicação e de queimaduras. Trabalhando na seção de tintura de panos, o operário José de Carvalho Junior foi vítima de um desses "riscos" da função:

\footnotetext{
Um operário com a perna esmagada

$\mathrm{Na}$ fabrica de tecidos Confiança Industrial, á rua Souza Franco, occorreuhontem um facto lamentavel.

O operario de José de Carvalho Junior trabalhava nas turbinas de pintura, quando uma dellas explodiu, queimando horrivelmente uma das pernas do infeliz, que ainda ficou esmagada, por ter sido colhida por um estilhaço.

O infeliz operario foi socorrido promptamente pelo medico da fabrica, que teve de lhe amputar a perna, sendo, em seguida, removido para a Santa Casa.

A administração da fabrica quizoccultar, o facto á policia do $16^{\circ}$ districto, não a conseguindo, porém, por não poder enviar para o necroterio a perna amputada sem guia daquelledistricto.

$\mathrm{Na}$ delegacia, logo se soube do caso, foi aberto inquérito. ${ }^{24}$
}

A tragédia sofrida por José de Carvalho explicita, de forma cruel, os riscos que eram apenas cogitados, revelando a violência do trabalho exercido. A Gazeta de Noticias ainda chama a atenção para o fato de que a administração da Fábrica Confiança, localizada em Vila Isabel, devido à gravidade do ocorrido, tentou não reportar o incidente às autoridades para impedir que uma investigação fosse iniciada. $\mathrm{Da}$ perspectiva dominante, os riscos seriam naturais e intrínsecos a algumas ocupações ou funções, portanto, os acidentes seriam lamentáveis, mas inevitáveis para o desenvolvimento capitalista. ${ }^{25}$

Devemos atentar também para a importância de refletir sobre a participação dos menores como força de trabalho e como vítimas da exploração capitalista. Eles recebiam as piores remunerações da hierarquia salarial adotada nas fábricas, por serem considerados aprendizes, mas estavam expostos aos mesmos riscos que os adultos. As crianças, rapazes e moças podiam ser alocados/as em seções com máquinas impróprias para suas estaturas, envolvendo graves riscos e perigos;

24 EXPLOSÃO. Gazeta de Noticias, Rio de Janeiro, $1^{\circ}$ nov. 1916. p. 6.

25 SILVA, Ana Beatriz Ribeiro Barros. Acidentes, adoecimento e morte no trabalho como tema de estudo da História. In: OLIVEIRA, Tiago Bernardon de (org). Trabalho e trabalhadores no Nordeste: análises e perspectivas de pesquisas históricas em Alagoas, Pernambuco e Paraíba [online]. Campina Grande, PB: EDUEPB, 2015. p. 224. 
ademais, eram designados/as a exercer atividades que, muitas vezes, exigiam esforço demasiado de sua parte, em relação à idade. ${ }^{26}$ Destaco, então, alguns casos em que tais explorações acarretaram acidentes:

Com um dedo esmagado - uma operaria

$\mathrm{Na}$ Fabrica de Tecidos Alliança, nas Laranjeiras, hontem, a operaria Sadz, menor de 9annos, foi colhida pela engrenagem de um tear, ficando com o dedo pollegar da mão direita esmagado. A referida menor, que é filha de Manuel Duarte, alli residente, foi socorrida na Assistencia, ficando em tratamento em sua propria casa $^{27}$.

Fracturou o braço

A pequena Eulina, de 11 annos, operaria da fabrica de tecidos Alliança, nas Laranjeiras, filha de Augusto Vieira da Silva, lidando com um carrinho de mão, escorregou e caiu, ficando com o braço direito fracturado.

Medicada pela Assistencia, recolheu-se á casa de seus pais, nos fundos da referida fabrica.

A policia do $6^{0}$ districto registrou o caso $^{28}$.

Colhida por um tear

A operaria Virginia Fernandes, menor de 14 annos de edade, residente á rua das Laranjeiras, n. 396, hontem na Fabrica de Tecidos Alliança, foi victima de um accidente.

Ao mover um tear, distrahiu-se e a engrenagem apanhou-lhe os dedos da mão direita, ferindo-os bastante.

Transportada para a Assistencia, foi medicada, seguindo depois para a sua residencia.

Do caso teve conhecimento a policia do 6을 Districto ${ }^{29}$.

Nota-se, então, que os três casos apresentados ocorreram com meninas menores de idade, que trabalhavam na Fábrica de Tecidos Alliança. Nas notícias, foi registrado que duas delas residiam próximas à fábrica, provavelmente seriam moradoras da vila operária. Nos casos de Virginia e Sadz, os acidentes ocorreram no manuseio do tear, o que revela a periculosidade dessa máquina e os riscos a que essas menores eram expostas ao executar tarefas consideradas leves, mas que, ao mínimo descuido, poderiam ocasionar acidentes irreversíveis. O acidente sofrido por Eulina pode ter sido ocasionado pelo próprio ambiente das fábricas têxteis, que, como mencionado anteriormente, ofereciam condições insalubres de trabalho, com seções quentes, úmidas e com partículas de algodão no ar. Chamo atenção também para a naturalização dos acidentes, na forma de registro por parte da grande imprensa. Ao noticiar que Eulina "escorregou e caiu" e Virginia "distrahiu-se e a engrenagem apanhou-lhe os dedos", os articulistas focalizaram mais a falta de

\footnotetext{
MOURA, op. cit., 1982, p. 50-51. ARAVANIS, op. cit., 2010, p. 169.

DESASTRES. Jornal do Brasil, Rio de Janeiro, 4 abr. 1912. p. 16.

FRACTUROU o braço. O Paiz, Rio de Janeiro, 20 jul. 1919. p. 4.

VARIOS desastres. Jornal do Brasil, Rio de Janeiro, 12 mar. 1914. p. 14.
} 
atenção e a distração das meninas do que propriamente a periculosidade das máquinas e os riscos causados pela insalubridade das fábricas.

$\mathrm{Na}$ indústria têxtil, o/a menor era alocado/a em funções que the exigiam responsabilidades e capacidades que ultrapassavam a própria noção de menoridade. Dele era esperado um comportamento condizente com sua condição de operário/a, ou seja, exigia-Ihe um perfil de adulto. Ao ser igualado com os adultos na condição de força de trabalho fabril, o/a menor seria investido de responsabilidade frente ao processo produtivo e, consequentemente, frente à situação de insegurança inerente a tal processo. ${ }^{30}$

Além dos acidentes decorrentes da atividade, devem-se ressaltar, inclusive, as brincadeiras e as práticas que desviavam a atenção da disciplina no espaço de trabalho como forma das crianças, rapazes e moças se desentediarem da rotina fabril e das extensivas jornadas. Procurando distraír-se, Alberto Pires da Silva e Raphael Martins Cardal iniciaram uma brincadeira que não acabou bem:

\section{Que brincadeira}

Na Fabrica de Tecidos Alliança deu-se hontem um desastre, do qual foi victima um menor de 11 annos e responsavel o hespanhol Raphael Martins Cardal.

Esse individuo estando a brincar com o menor Alberto Pires da Silva, como elleoperariodaquella fabrica e filho de Carlos Pires da Silva, residente no morro da Martha 17, o suspendeu no ar e deixando-o cahir, foi o menor bater com a cabeça em uma roda de uma das machinas, resultando disso uma grande fractura ${ }^{31}$.

As brincadeiras praticadas por menores no ambiente de trabalho também podem ser encaradas como forma de resistência ao disciplinamento aplicado nas fábricas. Considerando que os atos de diversão eram proibidos nesses locais de trabalho - por distrair o/a operário/a da tarefa a ser executada e por reduzir o tempo que a mão de obra passava junto às máquinas -, brincar nas fábricas poderia representar uma tentativa de obter lazer frente à exploração capitalista, que impunha ao corpo infantil uma lógica patogênica de trabalho até mesmo para os adultos.

Em 1911, a Academia de Medicina publicou um relatório em que propunha uma regulamentação do trabalho nas fábricas devido às condições em que se encontravam operários/as em estabelecimentos do Distrito Federal, considerando questões sanitárias, sociais e de saúde. No tocante ao emprego de menores, a Academia declarou:

Os aprendizes, na maioria das fabricas, não recebem uma instrucção profissional conveniente e seus serviços são

\footnotetext{
30 MOURA, Esmeralda Blanco B. de. Infância operária e acidente do trabalho em São Paulo. In: PRIORE, Mary del (org.). História das crianças no Brasil. São Paulo: Contexto, 1991.

31 QUE brincadeira. Gazeta de Noticias, Rio de Janeiro, 23 jan. 1904. p. 2.
} 
aproveitados abusivamente deum modo irregular, muitas vezes, exigindo-se esforços superiores ás forças da creança, sem proveito nenhum para a formação do futuro operário. ${ }^{32}$

Após visitas a fábricas da Capital Federal, os médicos da citada Academia procuraram denunciar que as crianças, apesar de serem empregadas na condição de aprendizes, eram extremamente exploradas e não recebiam instrução adequada para executar as atividades, o que poderia acarretar graves danos para sua integridade física, como acidentes de trabalho e prejuízos à saúde.

A falta de instrução adequada também foi elencada pelos operários como um dos principais motivos para a ocorrência de acidentes de trabalho. Durante o Congresso Operário Brasileiro, realizado entre 15 e 20 de abril de 1906, na sede do Centro Galego, à Rua da Constituição, nos 30 e 32, no Distrito Federal, foram discutidos diversos temas de interesse da classe operária e, dentre eles, a questão dos acidentes de trabalho. Abrindo o debate, tomou a palavra Benjamin Moisés Prins - membro da União Operária do Engenho de Dentro, naquele evento representando sua associação e o Centro Artístico Cearense ${ }^{33}$-, que destacou como vítimas mais frequentes as mulheres e as crianças, como se vê a seguir:

\begin{abstract}
Abre o debate o delegado Prins. Pensa que na sua maioria os accidentes são causados pela ignorancia e pela inesperiencia dos operarios, tanto assim que elles são mais frequentes entre as crianças e as mulheres. Termina propondo a creação de caixas de resistencia para soccorro nos accidentes. Avalia o systema por que os patrões procedem nos casos de accidentes. Em synthese não são os operarios os culpados dos accidentes, mas a burguezia que lhes rouba a educação a que desde pequenos tem direito. Parece-lhe que o meio de resolver o problema é obrigar o patrão a indemnisal-os de forma necessária sob pena de greve. ${ }^{34}$
\end{abstract}

Prins inicia sua fala culpabilizando as vítimas pelos acidentes sofridos nas fábricas e chamando atenção para a presença de mulheres e crianças no espaço produtivo de trabalho, parcela do operariado mais afetada pelos acidentes, por conta da ignorância e da falta de experiência na execução da atividade. Contudo, é importante atentar para o fato que, nesse período, homens, mulheres e menores aprendiam o trabalho executando as tarefas junto a operários/as mais antigos/as no estabelecimento. Então, a falta de experiência e a ignorância no trabalho também poderiam ser motivo para que homens adultos se acidentassem, visto que eles também eram expostos a atividades e a máquinas perigosas, sem uma preparação

32 UMA importante questão nacional. Correio da Manhã, Rio de Janeiro, 18 ago. 1911. p. 5.

33 PINHEIRO, Paulo Sérgio; HALL, Michael M. A classe operária no Brasil (1889-1930). Documentos, v. 1. São Paulo: Alfa Omega, 1979. p. 44-45.

34 OPERARIADO. Gazeta de Noticias, Rio de Janeiro, 20 abr. 1906. p. 2. 
anterior. No entanto, a partir de uma leitura a contrapelo, é possível conjecturar que Benjamin Prins entendesse que os homens seriam mais aptos ao trabalho produtivo em fábricas e oficinas e se adequassem melhor a tais atividades. Também eles estariam propícios a acidentes, mas em menor incidência, se comparados às mulheres e às crianças, considerados mais ignorantes em relação ao trabalho, pois não se encontravam em seus espaços "naturais".

Logo após o comentário inicial, entendendo que a responsabilidade pela ocorrência dos acidentes não era do operariado, o delegado sindical culpabilizou a burguesia por roubar a oportunidade de educação da classe operária, visto que as crianças deveriam trabalhar desde cedo para ajudar no sustento de suas famílias. Como proposta para amparar os/as acidentados/as, Prins sugere a criação de uma forma de seguro mantido pelos operários e propõe também a defesa pela indenização, que deveria ser paga pelos patrões, caso contrário ocorreria uma greve.

A defesa de greve, em caso de não pagamento de indenização por acidentes, se insere no modo reivindicativo defendido pelo congresso, que era o da ação direta. Edilene Toledo argumenta que a influência do sindicalismo revolucionário ${ }^{35}$ foi evidente no evento, vertente ideológica que norteou diversos movimentos sindicais em várias partes do mundo naquele período e que procurava reivindicar suas demandas por meio da ação direta. ${ }^{36}$

Outros delegados, cinco no total, representantes de associações de diversas categorias de trabalhadores, que haviam tomado a palavra para abordar o tema, destacaram a responsabilidade dos patrões e a defesa da indenização por meio de greve. O delegado Antonio Pinto Machado, presidente da União Operária do Engenho de Dentro entre 1903 e 1909, representando o Centro Artístico Cearense no congresso, se juntou aos demais na atribuição de responsabilidade aos patrões, mas também atribuiu parcela de culpa ao operariado "... pelo descaso com que procede ás vezes nas obras de que é encarregado". ${ }^{37}$

Deve-se perceber que apesar de responsabilizarem os patrões e cobrarem deles formas de assistência aos acidentados, os militantes que trataram da temática

\footnotetext{
35 “...os princípios do sindicalismo revolucionário são: 1) a revolução social, ou seja, a emancipação dos trabalhadores e trabalhadoras é o resultado das lutas das organizações sindicais e demais movimentos da classe trabalhadora; 2) defender o socialismo é defender a propriedade coletiva; 3 ) o socialismo é a livre federação das comunas e das associações da classe trabalhadora; 4) a greve geral é um instrumento para a emancipação da classe trabalhadora." In: DA SILVA, Selmo Nascimento. O sindicalismo revolucionário: suas origens, princípios e programa. Revista Estudos Literários (REL), UFRJ, vol. 1, 1ำsemestre de 2019. p. 110.

36 TOLEDO, Edilene. Primeiro Congresso Operário Brasileiro [verbete]. Disponível em: http://cpdoc.fgv.br/sites/default/files/verbetes/primeirarepublica/PRIMEIRO\%20CONGRESSO\%20OPER\%C3\%81RIO\%20BRASILEIRO.pdf. Acesso em: 28 jun. 2019.

37 OPERARIADO. Gazeta de Noticias, Rio de Janeiro, 20 abr. 1906. p. 2.
} 
dos acidentes em fábricas durante o Primeiro Congresso Operário Brasileiro também atribuíram certa parcela de culpa aos/às operários/as, naturalizando assim os riscos presentes em tais processos produtivos.

Após o debate e apresentação de moções à mesa condutora do congresso, a moção aprovada foi a do delegado Mota Assumpção, representante da Liga das Artes Gráficas, que dizia:

Considerando que o responsavel dos accidentes no trabalho é sempre o patrão; que as leis decretadas em prol dos trabalhadores sobre esta materia não têm nunca execução, são lettra morta; o Congresso aconselha os syndicatos que sempre que qualquer desastre se verifique, elles arbitrem a indemnisação que o patrão deve pagar, obrigando-o pela acçãodirecta. Para melhor prevenir os accidentes de trabalho devem os syndicatos fazer chegar ao conhecimento dos patrões as deliberações tomadas pelo Congresso. ${ }^{38}$

Complementando a moção de seu companheiro de liga, Luigi Magrassi acrescentou: "O $1^{\circ}$ Congresso Operario Regional Brasileiro affirma tambem que compete aos operarios o recusar-se a trabalhar quando julgarem que as condições em que o devem fazer não Ihes inspiram confiança". ${ }^{39}$ Em sua fala, Luigi reconhecia que a periculosidade estava presente na própria função a ser exercida e convocava os trabalhadores a terem responsabilidade por sua integridade física e a se recusarem a trabalhar em locais que lhes colocassem em risco.

É preciso ressaltar que as mulheres e os/as menores, também vítimas de acidentes ocorridos em fábricas e oficinas, não participaram do Primeiro Congresso Operário Brasileiro com direito de fala e, portanto, não proferiram discursos nos debates e nem tampouco propuseram moções, já que apenas os delegados poderiam discursar e fazer propostas. Dos 43 representantes de 28 sindicatos de diversas partes do Brasil, todos eram homens. ${ }^{40}$ No entanto, apesar do silenciamento, essa parcela do operariado não deixou de participar do congresso. Ao noticiar as discussões ocorridas no evento, o jornal Gazeta de Noticias informou que durante a sessão do dia anterior “... a vasta sala estava repleta. Viam-se pessoas de todas as classes, e até famílias foram assistir aos animados debates que hontem se feriram e que deram em resultado deliberações de caracter radical...". ${ }^{41}$ É possível

38 OPERARIADO. Gazeta de Noticias, Rio de Janeiro, 20 abr. 1906. p. 2.

39 Ibidem.

40 Conferir os nomes dos delegados e os sindicatos que representaram em: TOLEDO, Edilene. Primeiro Congresso Operário Brasileiro [verbete]. Disponível em: http://cpdoc.fgv.br/sites/default/files/verbetes/primeira-

republica/PRIMEIRO\%20CONGRESSO\%20OPER\%C3\%81RIO\%20BRASILEIRO.pdf. Acesso em: 28 jun. 2019; PINHEIRO, Paulo Sérgio; HALL, Michael M. A classe operária no Brasil 1889-1930. Documentos, v. 1. São Paulo: Alfa Omega, 1979. p. 44-45. 
pensar que as mulheres e os/as menores tiveram outras formas de participação no congresso, pois, presentes na assembleia, eles/as podem ter se manifestado por meio de aplausos, vaias e gritos.

Ao atentar para o registro das ocorrências de acidentes de trabalho publicado nos jornais, percebo que, em algumas circunstâncias, a imprensa atribuía certa ênfase ao "descuido", à "distração" ou à infelicidade dos/as operários/as:

Arthur de Oliveira, quando trabalhava em uma machina da fabrica de tecidos Alliança, foi tão infeliz, que esmagou nas engrenagens o dedo indicador da mão direita. ${ }^{42}$

Na Fabrica de Tecidos de Bangú trabalhava hontem o operario Miguel Rangel, de 50 annos, casado; brazileiro, morador naquella estação.

Rangel trabalhava com uma machina mas descuidou-se e teve a mão direita esmagada pela engrenagem. ${ }^{43}$

José Augusto Meda, perdeu hoje tres dedos quando se achava em serviço na fabrica de tecidos Cruzeiro, no Andarahy. Meda descuidando-se foi pilhado pela serra de uma machina, ficando sem tres dedos da mão direita ${ }^{44}$ (grifos meus).

Ao responsabilizar os/as executores/as das funções pelos acidentes ou atribuir culpa ao infortúnio, esses veículos de comunicação minimizavam o teor nocivo da exploração dos/as trabalhadores/as, enfatizavam o ato inseguro ao invés das condições inseguras e ofuscavam a responsabilidade de contramestres, mestres e chefes de seção na manutenção e/ou solicitação de substituição de maquinário com defeito.

Percebemos, então, que acidentes de trabalho não eram meros efeitos colaterais, mas parte integrante do processo de exploração capitalista e que poderia se manifestar de diversas formas, tanto pelas condições insalubres das fábricas, como pelo mau funcionamento das máquinas, pela falta de equipamentos de proteção, pelas condições exaustivas de trabalho, pelo sobretrabalho dispensado aos menores e pela periculosidade do maquinário e do processo produtivo.

No entanto, a partir do início de 1919, com a promulgação da lei de acidentes no trabalho, tais incidentes sofridos por operários/as passaram a ser tratados de outra forma:

Operaria ferida por uma lançadeira

$\mathrm{Na}$ fabrica de tecidos Confiança, trabalhava hontem, num tear, a operaria Maria das Dores Lemos, de 27 annos, brasileira, casada e residente na casa n. 23 da rua D. Elisa, em Villa Isabel, quando á 1 hora da tarde, mais ou menos a correia da machina arrebentou, arremessando longe uma lançadeira, que foi attingir o labio superior de Maria, produzindo um talho de seis centimetros. Aos gritos da operaria, accudiram as suas collegas, que chamaram o medico cirurgião da fabrica, dr. Henrique Guimarães, que prestou os serviços necessarios.

42 DESASTRE. Gazeta de Noticias, Rio de Janeiro, 19 jul. 1903. p. 2.

43 UM OPERARIO com a mão esmagada. A Razão, Rio de Janeiro, 19 jul. 1917. p. 4.

44 SEM os dedos. A Noticia, Rio de Janeiro, 27-28 ago. 1910. p. 2. 
O director-gerente da fabrica, Sr. Braga Netto, communicou o facto á policia do $16^{\circ}$ districto, que registrou os accidentes para os devidos effeitos da lei. ${ }^{45}$

Em virtude do acidente ter ocorrido após a promulgação do Decreto 3.724 , de 15 de janeiro de $1919,{ }^{46}$ que regulava as obrigações resultantes dos acidentes no trabalho, Maria das Dores teria direito a uma indenização; neste caso, a comunicação na delegacia de polícia era necessária para além do registro em si, era uma forma de dar entrada no direito conquistado por meio da lei.

\section{A promulgação da lei de acidentes de trabalho e sua aplicação}

Os anos de 1917 a 1920 foram marcados por greves de trabalhadores de diversos setores, que reivindicavam melhores condições de trabalho, redução das jornadas, aumento dos salários, diminuição dos custos dos produtos de primeira necessidade, regulamentação do trabalho das mulheres, retirada dos menores das fábricas, entre outras demandas, num contexto de intensificação da produção industrial, ${ }^{47} \mathrm{Tal}$ período também demarcou um processo de intervenção do Estado nas relações laborais, ação que teve início com iniciativas de discussão formal de medidas que procuravam regulamentar o trabalho, mas também, com a criação de órgãos governamentais cujo intuito era criar leis para o mundo do trabalho. Nessa conjuntura, a posição oficial do Estado em relação à questão social saiu de um tratamento simplesmente policialesco e avançou para um posicionamento de reconhecimento do problema da responsabilidade estatal. Nesse sentido, foi criada a Comissão de Legislação Social, na Câmara, no final de 1918, e promulgada a chamada lei especial, o decreto sobre Acidentes de Trabalho, em janeiro de 1919.48

O projeto de lei sobre acidentes de trabalho, de autoria do senador paulista Adolfo Gordo, fora apresentado em 1915; apesar de ter sido bem recebido pelo Centro Industrial Brasileiro, as discussões pertinentes não foram levadas adiante naquele ano. O projeto recebeu novo destaque por conta das mobilizações operárias de 1917 e o debate foi retomado naquela conjuntura. Buscando defender os

45 UM ACCIDENTE na Fabrica de Tecidos Confiança. Correio da Manhã, Rio de Janeiro, 30 mai. 1919. p. 3

46 Sobre este Decreto, ver: BRASIL. Decreto № 3.724, de 15 de janeiro de 1919. Regula as obrigações resultantes dos acidentes no trabalho. Disponível em: http://www2.camara.leg.br/legin/fed/decret/1910-1919/decreto-3724-15-janeiro-1919-571001publicacaooriginal-94096-pl.html. Acesso em: 28 jun. 2019.

47 Ver mais detalhes em: TOLEDO, Edilene. Um ano extraordinário: greves, revoltas e circulação de ideias no Brasil em 1917. Estudos Históricos, Rio de Janeiro, v. 30, no 61, p. 497-518, maio-agosto 2017.

48 GOMES, Angela de Castro. Burguesia e Trabalho. Rio de Janeiro: Editora Campus Ltda, 1979. p. 157. 
interesses industriais, o projeto foi reformulado e aprovado pela Comissão de Legislação Social em 1918, que teve como relator o deputado Andrade Bezerra. Já que o texto original apresentado pelo senador Adolpho Gordo enfrentava dificuldades de aprovação para integrar o projeto do Código do Trabalho, Andrade Bezerra formulou um projeto substituto, que conseguiu furar o bloqueio dos deputados contrários à totalidade da legislação trabalhista e foi aprovado como lei especial, ${ }^{49}$ sendo decretada pelo Congresso Nacional e sancionada pelo Presidente da República Delfim Moreira. ${ }^{50}$

O Decreto n. 3.724, de 15 de janeiro de 1919, obrigava os empregadores dos setores público e privado a pagar uma indenização ao/à operário/a ou à sua família, em caso de acidente ocorrido no exercício do trabalho, que acarretasse lesões corporais ou perturbações funcionais; ou que ocasionassem morte ou perda total, parcial, permanente ou temporária da capacidade para o trabalho. Também eram consideradas as moléstias contraídas exclusivamente pelo exercício do trabalho, quando a função as causasse e desde que determinasse o falecimento do operário ou perda total, parcial, permanente ou temporária de sua capacidade laboral. ${ }^{51}$

A promulgação da primeira lei de acidentes foi um importante passo para conferir cidadania e senso de direitos aos trabalhadores, em um período de relações de trabalho liberais, em que os acidentes eram naturalizados e considerados inerentes a algumas funções. Tal medida legal alterou as regras de relacionamento entre patrão e empregado, anteriormente pautadas nas condições oferecidas pelo contratante, uma vez que convocou os empregadores a se responsabilizar pela integridade física de seus funcionários. Os/as trabalhadores/as, por sua vez, contaram com um ato legal representativo de uma conquista, dentre as diversas demandas reivindicadas pela classe, para angariar condições mais dignas de trabalho, e imputaram custos aos patrões, em caso de danos sofridos no exercício de suas funções.

Em apoio ao decreto, que proporcionaria um amparo aos/às trabalhadores/as acidentados/as, Lourival Souto, um dos diretores da Fábrica de Tecidos Carioca, declarou: "É lei e acho que a nós, industriaes, só cabe tomarmos providenciaes para seu cumprimento. Demais, o trabalho do governo está bem feito e nada se tem de

49 FERRAZ, op. cit., p. 207, 209-210.

50 BRASIL. Decreto № 3.724, de 15 de janeiro de 1919. Disponível em: https://www2.camara.leg.br/legin/fed/decret/1910-1919/decreto-3724-15-janeiro-1919-571001publicacaooriginal-94096-pl.html. Acesso em: 28 jun. 2019.

51 Ibidem. 
arguir contra elle". ${ }^{52}$ Não obstante as palavras em aprovação à medida legislativa, sua efetivação parece ter representado uma nova luta a ser travada.

Apesar da aparente "boa vontade" dos industriais em apoiar tal medida legal, para além da promulgação do decreto era preciso que a lei fosse executada e as indenizações fossem pagas. No entanto, ao que as evidências indicam, os/as operários/as enfrentaram dificuldade para que a lei fosse colocada em prática. Assim, na "Columna Operaria" do jornal $A$ Epoca, foi denunciado seu descumprimento:

A lei dos accidentes no trabalho não é respeitada - Aos directores da Fabrica de Tecidos Carioca

É o caso do fallecimento do trabalhador Hypppolito de Barros, ocorrido no dia $1^{\circ}$ de setembro findo, a que nos vamos referir.

Em fins do mez de agosto do corrente anno, quando trabalhava, no serviço de descarga de uma carroça, aconteceu machucar-se gravemente 0 ajudante de carroceiro da Fabrica de Tecidos Carioca Hyppolito de Barros, na occasião em que servia á casa do negociante Seraphim de tal, no Leblon.

Tão graves foram os feridos recebidos que o infeliz operarioveiu a fallecer, dias depois.

A despeito de se tratar de um caso perfeitamente definido na lei que regula os accidentes de trabalho, até o presente momento nenhuma providencia foi dada para ser cumprida a referida lei. Tanto a policia quanto a propriadirectoria da Carioca estão na obrigação de explicar essa situação, porque, antes de tudo, tratase, ao que parece, de burlar uma lei que foi feita para produzir beneficios resultados á classes trabalhadoras, muito embora contrarie aos potentados. ${ }^{53}$

Apesar do suposto apoio por parte dos industriais, transparente na fala do proeminente Lourival Souto, ao dar força a tal iniciativa, Hyppolito de Barros, ajudante de carroceiro da fábrica na qual Souto compunha a diretoria, faleceu na execução de seu trabalho; sem embargo, mais de dois meses depois, nenhuma providência havia sido tomada para assegurar seus familiares, posto que, segundo o artigo $7^{\circ}$, eles teriam direito a uma indenização:

Art. $7^{\circ}$ Em caso de morte a indemnização consistirá em uma somma igual ao salario de tresannos da victima, a qual será paga de uma só vez á sua familia, conjuge sobrevivente e herdeiros necessarios, observadas as disposições do Codigo Civil sobre a ordem da vocação hereditaria e mais $100 \$$ para as despezas de enterramento. ${ }^{54}$

A denúncia publicada em $A$ Epoca é um exemplo da importância da imprensa como espaço de luta por direitos, por parte dos/as trabalhadores/as. Sendo este um jornal que trazia colunas como "Nos Suburbios", que noticiava o cotidiano e as

52 UMA grande reforma social. A Noite, Rio de Janeiro, 14 mar. 1919. p. 1.

53

COLUMNA operaria. A Epoca, Rio de Janeiro, 09 nov. 1919. p. 6.

54 BRASIL. Lei № 3.724, de 15 de janeiro de 1919.

Revista Mundos do Trabalho | Florianópolis | vol. 11 | 2019 | p. 1-22 
condições de vida da população suburbana, e "Columna Operaria", que abordava questões sociais e trabalhistas, com artigos assinados, muitas vezes, por militantes operários, A Epoca foi um veículo de comunicação utilizado pelos/as trabalhadores/as para que suas demandas e pautas chegassem ao conhecimento de um público mais amplo e para pressionar os patrões e o poder público.

Ao que parece, a "dificuldade" em cumprir a lei, colocando em prática o pagamento das indenizações, não era exclusividade dos industriais têxteis. No Centro dos Empregados em Ferrovias, a secretaria publicou a seguinte declaração:

Se é verdade que a lei dos accidentes no trabalho é uma burla aos trabalhadores, isso porque as quantias nella prefixadas como indemnisações ás victimas são irrisoriastambem é verdade que é digno de elogios o patrão que paga o que ella determina sem lançar mão do recurso da chicana forense. ${ }^{55}$

Com esta afirmação, a secretaria do Centro denunciava que os patrões procuravam recorrer, por via legal, do pagamento das indenizações, em casos de acidentes, e os que pagavam as compensações financeiras previstas em lei, consideradas pelos operários como irrisórias, eram merecedores de elogios. Em relação aos valores das indenizações, o $2^{\circ}$ Secretário da União dos Operários em Fábricas de Tecidos, o tecelão Antenor Faria criticou:
A Lei de accidentes do Trabalho é boa, e bem fundada, porém os seus artigos $3^{\circ}$ e $14^{\circ}$ são antagonicos aos operarios porque mandam dar trezentos dias de ordenado por anno ao operariovictima do trabalho, não podendo o ordenado exceder 2:400\$ por anno, muito embora seu ordenado seja maior antes do accidente... ${ }^{56}$

O sindicalista reconhecia a importância da lei, mas destacava que o limite dos valores para as indenizações anuais era prejudicial aos operários acidentados, que recebiam remunerações mais altas quando estavam em atividade.

Entretanto, se num primeiro momento havia indícios de que alguns industriais têxteis dificultaram o pagamento das indenizações aos/às operários/as acidentados/as, no final do ano seguinte, aqueles que faziam parte do Centro Industrial de Fiação e Tecelagem do Algodão fundaram uma cooperativa, cuja finalidade era compensar os encargos provenientes da lei de acidentes no trabalho, denominada Sociedade Cooperativa de Seguros Operários em Fábricas de Tecidos. A criação de tal associação e seus estatutos foram aprovados pelos membros fundadores em assembleia geral, realizada em 6 de dezembro de 1920, mas seu

\footnotetext{
55 MOVIMENTO operario. A Razão, Rio de Janeiro, 25 ago. 1919. p. 6.

56 A LEI de accidentes no trabalho perante as classes operarias. A Razão, Rio de Janeiro, 15 mar. 1919. p. 1.
} 
funcionamento só foi oficializado pelo Decreto n.14.680, de 21 de fevereiro de 1921, segundo o qual a sociedade funcionaria com a responsabilidade limitada de fornecer seguros para os operários, além de ter aprovado seus estatutos. ${ }^{57}$ Entre suas diretrizes constavam:

Art. $2^{\circ}$ - É objecto principal da sociedade operar, na fórma da legislação respectiva, em seguros contra accidentes de trabalho, quer para o pagamento das indemnizações, quer para a prestação de soccorrosmedicos, pharmaceuticos e hospitalares, tudo em relação aos operarios das fabricas de tecidos de seu socios.

Art. $6^{\circ}$ - Os socios serão de responsabilidade limitada pelo valor de suas acções e só poderão ser como tal admittidos as sociedades de qualquer natureza ou os particulares que possuirem ou explorarem fabricas de fiação e tecelagem do algodão no Districto Federal e Estado do Rio de Janeiro.

8 - Além das importancias com que contribuiem para o capital social, entrarão os socios para a caixa com as quotas mensaes de $\$ 300$ por operario a serviço de sua respectiva fabrica, podendo a directoria, de accordo com o conselho fiscal, conforme as circumstancias, modificar, para mais ou para menos, a importancia dessa quota. ${ }^{58}$

A referida associação deveria ser composta de sócios proprietários de fábricas de fiação e tecelagem no Distrito Federal e em todo o estado do Rio de Janeiro, e seu objetivo principal se articulava em torno do pagamento de indenizações aos/às acidentados/as e da prestação de serviços médicos, farmacêuticos e hospitalares. Cada companhia associada deveria contribuir, inicialmente, com uma quantia para o capital social e, mensalmente, com o valor de $\$ 300$ por operário/a assegurado/a. Mas tal quantia mensal foi progressivamente aumentada ao longo dos anos. Segundo Ana Beatriz Ribeiro Barros Silva, essas seguradoras, além de atenderem parcialmente às exigências de leis sociais, proporcionaram grandes vantagens econômicas aos industriais, o que explica a sua existência até os anos 1960, apesar das tentativas de reforma. ${ }^{59}$

No primeiro ano de funcionamento da sociedade, estavam assegurados 24.269 operários/as, empregados/as das seguintes companhias associadas:

Companhia America Fabril, Companhia de Fiação e Tecidos Alliança, Companhia Brasil Industrial, Companhia de Fiação e Tecidos Confiança Industrial, Companhia de Fiação e Tecidos Cometa, Companhia de Fiação e Tecidos Corcovado, S. A. CotonificioGavea, S. A. Fabrica de Tecidos Esperança, Companhia Fiação e Tecidos Industrial Campista, Companhia Manufactura Fluminense, Companhia de Fiação e Tecidos

57 BRASIL. Lei n. 14.680, de 21 de fevereiro de 1921. Concede autorização para funcionar na República a Sociedade Cooperativa de Seguros Operários em Fabricas de Tecidos e aprova os seus estatutos. Disponível em: https://www2.camara.leg.br/legin/fed/decret/1920-1929/decreto-1468021-fevereiro-1921-512336-publicacaooriginal-1-pe.html. Acesso em: 30 jun. 2019.

58 RELATÓRIOS da Sociedade Cooperativa de Seguros Operarios em Fabricas de Tecidos - 1921-1926. Rio de Janeiro: Sindicato da Indústria da Fiação e Tecelagem do Estado do Rio de Janeiro. p. 3-6.

59 SILVA, op. cit., p. 234. 
Magéense, Companhia Petropolitana, Companhia Progresso Industrial do Brasil, Companhia N. F. Fiação e Tecidos Santo Aleixo, Companhia Tecidos de Linho de Sapopemba e The Rio de Janeiro Flour Mills \& Granaries (Moinho Inglez). ${ }^{60}$

As companhias apresentadas nessa listagem estavam distribuídas pelo Distrito Federal e outras localidades do estado do Rio de Janeiro, como Paracambi, Petrópolis e Magé. Lourival Souto assumiu a presidência da sociedade em seu primeiro ano de funcionamento, mas pediu demissão do cargo em 19 de março de 1923. Para ocupar seu lugar na função, foi convidada a Companhia América Fabril, que contava com fábricas na Capital Federal e em Magé e indicou seu diretor, Carlos Telles da Rocha Faria, cujo serviço foi prestado até, pelo menos, $1927 .{ }^{61}$

Como mencionado nos estatutos, a taxa paga por operário/a pelas companhias era de $\$ 300$, no entanto, logo no primeiro ano de funcionamento da sociedade verificou-se que, devido ao alto número de acidentes a serem indenizados, a taxa deveria ser aumentada, o que ocorreu progressivamente ao longo dos anos, passando a ser cobrado o valor de $\$ 400$, em 1921; $\$ 500$, em 1922; $\$ 700$, em 1923; e fixada em $\$ 600$ a partir de $1924 .{ }^{62}$

Em relação à atuação da Sociedade Cooperativa de Seguros Operários em Fábricas de Tecidos, entre os anos de 1921 e 1926, baseada em informações encontradas nos relatórios da associação, torna-se possível analisar o seguinte quadro:

\begin{tabular}{|l|c|c|c|c|c|c|}
\hline & 1921 & 1922 & 1923 & 1924 & 1925 & 1926 \\
\hline $\begin{array}{l}\text { Número de operários } \\
\text { assegurados (por volta de) }\end{array}$ & 24.269 & 24.794 & 25.010 & 21.731 & 23.990 & 22.662 \\
\hline Acidentes ocorridos & 709 & 1.051 & 1019 & 852 & 702 & 746 \\
\hline $\begin{array}{l}\text { Acidentes pagos } \\
\text { Mortes pagas }\end{array}$ & 608 & 624 & 944 & 890 & 709 & 599 \\
\hline $\begin{array}{l}\text { Incapacidades } \\
\text { permanentes pagas }\end{array}$ & 15 & 19 & 60 & 37 & 47 & 36 \\
\hline $\begin{array}{l}\text { Incapacidades temporárias } \\
\text { pagas }\end{array}$ & 591 & 603 & 880 & 851 & 659 & 562 \\
\hline
\end{tabular}

Fonte: Sindicato da Indústria da Fiação e Tecelagem do Estado do Rio de Janeiro (1927). Relatório relativo ao ano de 1926. In: RELATÓRIOS, op. cit.

No tocante ao número de operários/as assegurados/as pela Sociedade, observamos que ocorreu progressivo aumento entre 1921 e 1923 e uma queda considerável entre 1923 e 1924. O curioso desse decréscimo em 1924 deve-se que, naquele ano, passou a fazer parte da Sociedade mais uma fábrica têxtil, a Companhia Nacional de Tecidos Nova América e nenhuma das companhias

\footnotetext{
60 RELATÓRIOS, op. cit., p. 6.

61 Ano final de abrangência do livro "Relatório relativo ao ano de 1921". In: RELATÓRIOS, op. cit.

62 RELATÓRIOS, op. cit.
} 
acionistas desde 1921 haviam se retirado da associação. Provavelmente, tal redução na quantidade de assegurados deveu-se ao aumento do valor pago por operário, chegando a $\$ 700$, a taxa mais alta do período analisado. Além disso, pode-se conjecturar que, por conta do grande número de acidentes ocorridos em 1923 e da alta quantidade de indenizações pagas naquele ano algumas companhias tenham optado por desassegurar aqueles que estivessem correndo menos risco. Ainda, deve-se atentar para o fato de que, em 1924, o número de acidentes ocorridos foi menor do que o de acidentes pagos, o que nos permite refletir que incidentes ocorridos em 1923 passaram por uma investigação e suas indenizações só foram pagas no ano posterior. Como consequência, as companhias reduziram o número de operários/as assegurados/as em 1924, cujo critério para retirada desses/as trabalhadores/as da cobertura da sociedade não foi explicitado. No ano seguinte, o número de assegurados voltou a aumentar tendo, possivelmente, como um dos motivos a entrada da Companhia Fábrica de Tecidos Dona Izabel na Sociedade.

Quanto ao número de acidentes apresentados nesta tabela, podemos afirmar que a periculosidade das fábricas de tecidos era elevada, na década de 1920, visto que o menor quantitativo contabilizado foi registrado em 1925, com 702 casos, o que dava uma média de 39 acidentes por companhia naquele ano (18 companhias acionistas) e no ano ápice, 1923, ocorreu uma média de 63,68 casos de acidentes por companhia (16 companhias acionistas). No tocante aos acidentes pagos, o ano de 1923 também merece destaque, com o maior número de mortes e incapacidades permanentes da amostra. Após aquele ano, a quantidade de acidentes pagos diminuiu progressivamente, embora, em 1926, a ocorrência de acidentes tenha voltado a crescer. Destaco também que, em 1924 e 1925, o número de acidentes pagos foi maior que o de acidentes registrados; como mencionado anteriormente, tal fenômeno deve ter ocorrido em virtude dos pagamentos de indenizações retroativas.

\section{Considerações finais}

Historicamente, os embates entre a exploração capitalista do trabalho e o movimento operário explicitaram a relevância da questão social, o que acarretou a proposição de debates que levaram ao reconhecimento dos direitos sociais voltados para reduzir a exploração desenfreada da força de trabalho que, caso não minimizada, pode resultar em doenças, acidentes de trabalho e até mesmo morte. Nesse sentido, procuro nesse artigo chamar a atenção para o centenário da lei de acidentes de trabalho promulgada em 1919, por representar um marco inicial de 
conquistas no campo da legislação social e um ponto de partida para medidas que visavam à proteção e à saúde no trabalho.

Essa interferência do Estado nas relações capital-trabalho, na forma de lei, em plena República liberal e oligárquica, representou simbolicamente o início das mudanças nas relações de convivência e reciprocidade entre patrões e empregados, visto que, a partir daquele momento, os/as trabalhadores/as passaram a contar com uma medida legislativa que Ihes reconhecia como detentores de direitos e thes assegurava respeito quanto à integridade física no trabalho. É preciso perceber essa lei como uma primeira conquista da classe trabalhadora contra a herança da tradição e do pensamento escravocrata nas relações de trabalho.

Por meio do associativismo, de seus modos de mobilização e de sua capacidade de pressionar através da imprensa e do poder público, os/as trabalhadores/as traçaram um caminho de construção de sua própria cidadania, nas primeiras décadas do século $X X$, tendo a lei de acidentes de trabalho como um marco importante.

Torna-se necessário, assim, salientar esta história centenária de lutas por direitos por parte dos/as trabalhadores/as, em tempos de perseguição aos direitos trabalhistas pelas autoridades políticas do século XXI, de modo que não se apague o papel histórico do operariado de ontem e de hoje.

Recebido em 07/07/2019

Aprovado em 26/09/2019 